\title{
Study on mechanical properties of a new type of prefabricated GRC mold shell
}

\author{
Chen Dong ${ }^{1}$, Chen Ming ${ }^{2,}$, , Cai Ouyang ${ }^{3}$, and Li Pengkun ${ }^{4}$ \\ ${ }^{1}$ School of civil engineering, Anhui Jianzhu University, Anhui Hefei, 230601, China \\ ${ }^{2}$ School of civil engineering, Anhui Jianzhu University, Anhui Hefei, 230601, China \\ ${ }^{3}$ School of civil engineering, Anhui Jianzhu University, Anhui Hefei, 230601, China \\ ${ }^{4}$ School of civil engineering, Anhui Jianzhu University, Anhui Hefei, 230601, China
}

\begin{abstract}
The GRC formwork structural column adopts the factory-based vertical prefabrication production process, which can reduce the floor space, reduce the formwork loss, speed up the construction progress, promote the full decoration of the prefabricated building, and improve the efficiency of the assembly construction. major. In order to optimize the production process of prefabricated GRC formwork column, the overall stress system of GRC formwork structure is analyzed in the concrete pouring process, and the thickness of GRC formwork, the number of steel hoops and the GRC mode are considered. The influence of the shell cross-section size on the mechanical properties. The research results can provide reference for the optimization and design of prefabricated GRC formwork column production process.
\end{abstract}

\section{Introduction}

In recent years, the new prefabricated concrete industrial building has been in a high-speed development period under the active promotion of the government with its green environmental protection, energy conservation and consumption reduction, high construction efficiency, short construction cycle, easy to ensure the quality of factory operations and other characteristics.

The traditional GRC material is easy to crack, which would reduce the bearing capacity and durability of the material, and seriously threaten the safety of people 's lives and property. In order to optimize the production process of prefabricated GRC components and improve the production efficiency of GRC components, the crack resistance of GRC materials was studied experimentally, and the finite element model of the whole force system of GRC shell structure column was established and analyzed, which provided a reference for the optimization and design of the production process of prefabricated GRC shell structure column.

\section{The crack resistance study on GRC material}

Due to the construction of cement concrete materials, the self-deformation problem and structural limitation of cementitious materials, the GRC materials are easy to crack in the environment with large temperature and humidity changing. This will reduce the bearing capacity and durability of GRC material and will have adverse effects on the outlook of the material. Taking these factors into consideration, hereby the influence of fiber, tire powder and expansive agent on the crack resistance of GRC material with the traditional material formula is studied. The raw materials used in the study experiment include: cement, coal ash, river sand, superplasticizer, modified and highly dispersed alkali-resistant glass fiber and tap water.

\subsection{Experiment ideas}

When the shrinkage of cement materials existing in GRC materials is limited, the tensile stress will be generated. When this tensile stress is larger than the GRC material's tensile strength, GRC materials will break. Thus, the following two measures shall be taken to improve the crack resistance of GRC materials: decreasing the shrinkage and improving the tensile strength. The traditional GRC material formula shall be adjusted correspondingly by adding expansive agent, tire powder and modified highly dispersed alkali-resistant glass fiberso as to prepare the experiment piece of $40 \mathrm{~mm} * 40$ $\mathrm{mm} * 160 \mathrm{~mm} / 25 \mathrm{~mm} * 25 \mathrm{~mm} * 280 \mathrm{~mm}$. The microstructure of the experiment pieces is analyzed by XRD, DSC-TG, MIP and SEM methods.

\subsection{Experiment process}

The study is aimed to analyze the influence of fiber content, tire powder content and expansive agent on the shrinkage and mechanical properties of GRC materials. In the experiment, the fiber, tire powder and expansive agent are separately mixed together with the cement for 3 minutes. The water and cement ratio shall be controlled

"Corresponding author: 851737416@qq.com 
at 0.28 . Then, the water and sand shall be mixed together evenly based on the cement mortar preparing standard and the GRC flowing shall be controlled at $180 \mathrm{~mm}$ (flow table method). Keep the $25 \mathrm{~mm} \times 25 \mathrm{~mm} \times 280 \mathrm{~mm}$ test piece under standard environment (temperature is $20^{\circ} \mathrm{C} \pm 2^{\circ} \mathrm{C}$ and relative humidity is $95 \%$ or higher) for one day and demould it. Then, place the test piece into the curing box with certain temperature and humidity. The temperature of cure box shall be controlled at $20^{\circ} \mathrm{C}$, and the constant temperature and humidity conditions shall be maintained to cure the test piece. Use the length measurement instrument to test the dry shrinkage property of the test piece. After then $40 \mathrm{~mm} \times 40 \mathrm{~mm} \times 160$ $\mathrm{mm}$ test piece is prepared, cure it under standard environment for one day. Then, place the test piece into the curing box with certain temperature and humidity. The temperature of cure box shall be controlled at $20^{\circ} \mathrm{C}$. The press test device is used to test the compression resistance and bending resistance of the test piece. To analyze the influence of humidity conditions, the cure box with $40 \%$ and $70 \%$ humidity are separately used in the experiment.

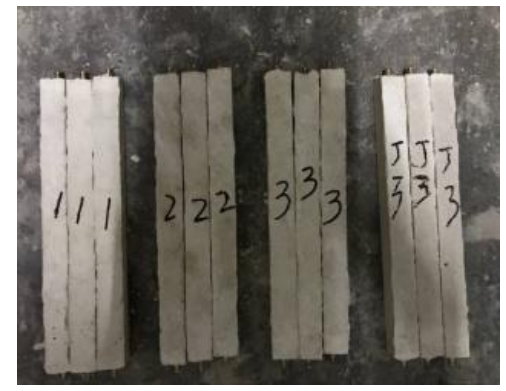

Fig. 1 Dry shrinkage property test piece

\subsection{The influence of fiber content on the dry shrinkage and mechanical property of GRC materials}

\section{(1) Dry shrinkage property}

The picture 2 displays the shrinkage performance of GRC materials with different fiber contents separately under $40 \%$ and $70 \%$ humidity conditions. It can be seen from the picture that when the relative humidity is controlled at $40 \%$ and $70 \%$, the adding of fiber content has rare influence on the shrinkage of GRC materials. However, when the relative humidity increases from $40 \%$ to $70 \%$, the 28 -day shrinkage can reduce by $40 \%$. Thus, it can be seen that the humidity increasing is greatly benefit for the reducing of the shrinkage of GRC test piece. Therefore, the curing humidity can be increased by soaking, immersing or other methods in curing process so as to obviously decrease the dry shrinkage of GRC materials.

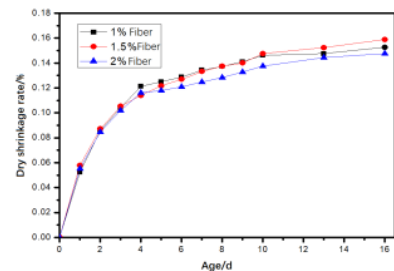

(a) $\mathrm{RH}=40 \%$

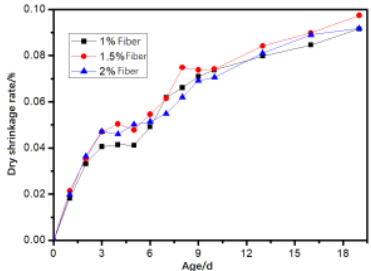

(b) $\mathrm{RH}=70 \%$
Fig. 2The influence of fiber content on the dry shrinkage of GRC materials

(2) Mechanical property

Fig. 3 shows the compression ratio of GRC specimens with different fiber content when the relative humidity is $40 \%$ and $70 \%$. From figure 3 (a), it can be seen that with the increase of age, the overall compression ratio increases rapidly from $0 \mathrm{~d}$ to $7 \mathrm{~d}$, but increases slowly at 7 to $28 \mathrm{~d}$, which indicates that the anti-folding strength of the fiber is greatly improved at 7 $\mathrm{d}$ of cement hydration. In addition, the $1 \%$ fiber content shows the highest folding ratio. As can be seen from figure 3 (b), when the compression ratio of GRC is analyzed at $70 \%$ relative humidity, $1 \%$ fiber still has a relatively large compression ratio. It can be seen that the content of $1 \%$ fiber can significantly improve the toughness of GRC and improve its crack resistance.

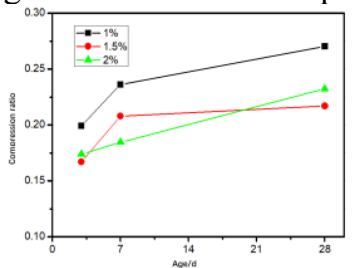

(a) $\mathrm{RH}=40 \%$

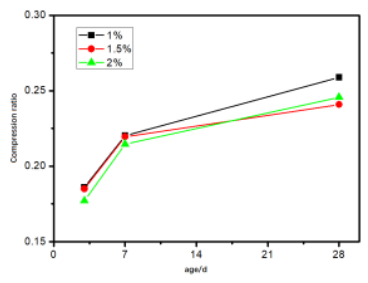

(b) $\mathrm{RH}=70 \%$
Fig. 3Effect of fiber content on GRC compression ratio

\subsection{Effect of rubber powder content on dry shrinkage and mechanical properties of GRC}

(1) Dry shrinkage performance

Fig. 4 shows the dry shrinkage of GRC specimens with different amount of rubber powder when the relative humidity is $40 \%$ and $70 \%$. It can be seen from figure 4 (a) that the shrinkage of GRC also increases significantly with the increase of rubber powder content at $40 \%$ relative humidity. The dry shrinkage value increased rapidly within 0 to 7 days. And slowed down obviously after 7 days. The shrinkage characteristics of GRC at $70 \%$ relative humidity were consistent with those at $40 \%$ relative humidity. However, compared with the dry shrinkage of GRC at $40 \%$ relative humidity, the shrinkage rate of GRC at $70 \%$ relative humidity is very small. 


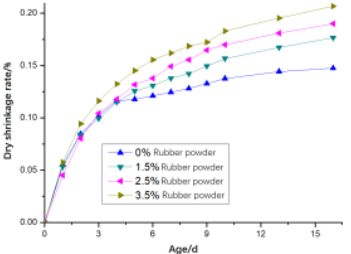

(a) $\mathrm{RH}=40 \%$

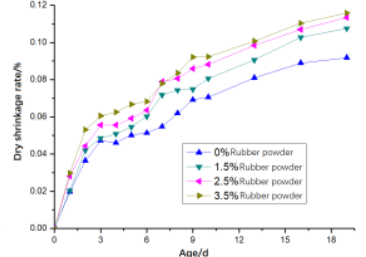

(b) $\mathrm{RH}=70 \%$

Fig. 4 Effect of rubber powder content on drying shrinkage

(2) Mechanical property

Fig. 5 shows the compression ratio of GRC at different rubber powder contents when the relative humidity is $40 \%$ and $70 \%$. It is shown that the pressure ratio of GRC at $70 \%$ relative humidity is slightly higher than that of GRC at $40 \%$ relative humidity. At the same time, it can be found that when the content of rubber powder is $2.5 \%$, GRC has the highest compression ratio at 28 days. Therefore, $2.5 \%$ rubber powder content can effectively improve the toughness and crack resistance of GRC.

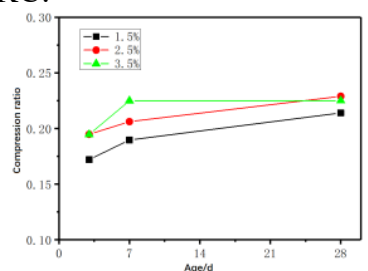

(a) $\mathrm{RH}=40 \%$

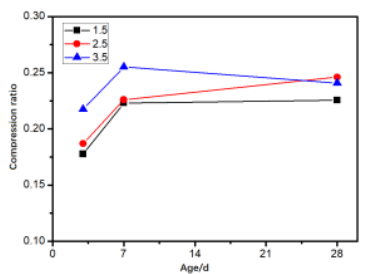

(b) $\mathrm{RH}=70 \%$
Fig. 5Effect of rubber powder content on GRC folding ratio

\subsection{Improvement of dry shrinkage performance of GRC by expansive agent}

Fig. 6 shows the effect of expansive agent on dry shrinkage in different humidity environment. It can be seen from the diagram that when the relative humidity is $40 \%$, the dry shrinkage value of GRC is obviously higher than that of GRC at $70 \%$ relative humidity, which indicates that the dry shrinkage performance will be improved obviously by increasing the curing humidity. At the same time, it can be seen from the diagram that the drying shrinkage value of GRC is significantly lower than that of unmixed UEA expansive agent at $40 \%$ relative humidity. At 15 days, the dry shrinkage value of GRC mixed with UEA expansive agent was lower than that of GRC specimens cured at $70 \%$ humidity. Therefore, the dry shrinkage characteristics of GRC can be effectively improved by adding a certain amount of expansive agent, thus improving its crack resistance.

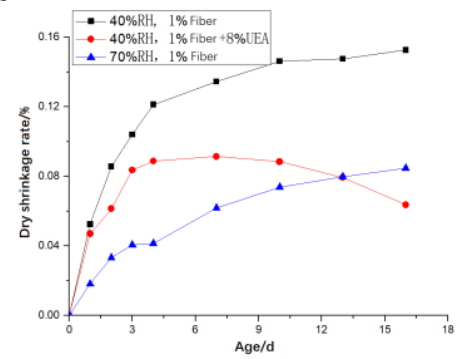

Fig. 6Effect of expansive agent on dry shrinkage of GRC in different humidity environment

\section{Production process of structural column of GRC formwork}

Prefabricated GRC structural columns are fabricated by vertical prefabricated production process of factory: Firstly, reinforcing cage is tightly fixed on the installation base, then install electromechanical pipelines and embedded parts, and GRC formwork is hung on the periphery of reinforcing cage, meanwhile arrange and fix steel hoops from bottom to top outside the GRC formwork, finally pour and cure concrete, and complete subsequent transportation and on-site installation work.

\section{Research on Mechanical Properties of GRC formwork Column}

\subsection{Model parameters}

The formwork of GRC structural column described in this paper has a thickness of $20 \mathrm{~mm}$, a height of $4200 \mathrm{~mm}$ with a base steel plate in size of $750 \mathrm{~mm} \times 750 \mathrm{~mm} \times 100 \mathrm{~mm}$, and GRC formwork is vertically placed on the steel plate base. The height and thickness of rectangular steel hoops are both $50 \mathrm{~mm}$, which are uniformly arranged on the outer surface of GRC formwork according to arrangement from bottom to top, wherein the distance between adjacent steel hoops is $830 \mathrm{~mm}$.

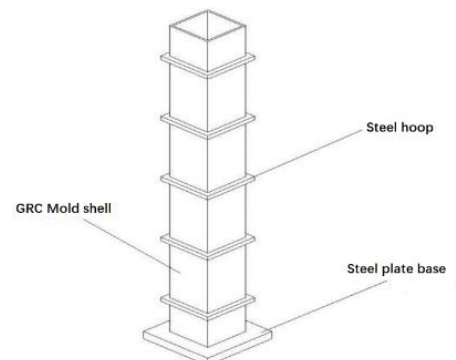

Fig.7Structural column of GRC formwork

\subsection{Establishment of Finite Element Model}

Prefabricated GRC structural column uses GRC formwork as outer mold of GRC components, which has a steel plate base at bottom for support and steel hoops arranged from bottom to top outside. The whole structure forms an integral stress support system. In ABAQUS software, three components need to be established, including GRC formwork, steel hoop and steel plate base, and these three components are all discretized by three-dimensional tetrahedral solid element. Create the attributes of GRC and steel and assign these attributes to the above three components. Finally, assemble the three components together. Then complete the setting of analysis steps, and set output variables such as U-displacement, S-von-mises, E, i.e. output displacement, stress and strain. The plane connecting GRC formwork and steel hoop is defined as interaction (contact), so as to ensure ABAQUS software can identify the interrelation between these components. And create boundary conditions and loading settings, set the bottom surface of 
steel plate base to be completely fixed, so as to simulate actual situation, and apply calculated load values to 4 inner sides of GRC formwork structure vertically respectively. Finally, after dividing grids, create an analysis job and submit it to system for analysis.

\subsection{Load Calculation of Structural column of GRC formwork}

(1) As mentioned in paragraph 4.1.1 of JGJ162-2008 "Technical Code for Safety of Building Construction Formwork", the calculation formula of maximum lateral pressure of newly poured concrete acting on the formwork is as follows, and smaller value is taken.

$$
\begin{aligned}
& F=0.22 \gamma_{c} t_{0} \beta_{1} \beta_{2} V^{\frac{1}{2}} \\
& F=\gamma_{c} H
\end{aligned}
$$

Meanings and values of each parameter in the formulas are as follows:

\begin{tabular}{|l|c|c|}
\hline Parameter & $\begin{array}{l}\text { Taken } \\
\text { Value }\end{array}$ & Unit \\
\hline (Gravity density of concrete) $\gamma_{c}$ & 25 & $\mathrm{KN} / \mathrm{m} 3$ \\
\hline $\begin{array}{l}\text { (Initial setting time of newly poured } \\
\text { concrete) } t_{0}\end{array}$ & 5 & $\mathrm{~h}$ \\
\hline $\begin{array}{l}\text { (Correction coefficient of additive } \\
\text { influence) } \beta_{1}\end{array}$ & 1.0 & $/$ \\
\hline $\begin{array}{l}\text { (Correction coefficient of slump } \\
\text { influence) } \beta_{2}\end{array}$ & 1.15 & $/$ \\
\hline (Pouring speed of concrete) $\mathrm{V}$ & 0.5 & $\mathbf{m} / \mathbf{h}$ \\
\hline $\begin{array}{l}\text { (Total height of concrete in } \\
\text { formwork) } \mathrm{H}\end{array}$ & 4.2 & $\mathbf{m}$ \\
\hline
\end{tabular}

The values taken of the parameters in the above table are applied to Formula (3.1.1), and the following result is obtained: $F=0.22 \times 25 \times 1.0 \times 1.15 \times 0.5^{\frac{1}{2}}=22.4 \mathrm{kN} / \mathrm{m}^{2}$

Applying these values taken to Formula (3.1.2), the following result is obtained: $F=25 \times 4.2=105 \mathrm{kN} / \mathrm{m}^{2}$

Taking the smaller of the above two results, the maximum lateral pressure of newly poured concrete acting on the formwork is: $22.4 \mathrm{kN} / \mathrm{m}^{2}$

According to the provision for determining the standard value of live load in Paragraph 4.1.2 of JGJ162-2008 "Technical Code for Safety of Building Construction Formwork", when pouring concrete, the horizontal load generated by newly poured concrete on vertical formwork shall be determined as follows: $4 \mathrm{kN} / \mathrm{m}^{2}$

(3) As described in paragraph 4.3.2 of JGJ162-2008 "Safety Technical Specifications for Building Construction Forms", when the formwork involved in the calculation is a formwork of large-volume structure (column (side length greater than $300 \mathrm{~mm}$ ), wall (thickness greater than $100 \mathrm{~mm}$ )), the load categories of participating combinations are:

When calculating bearing capacity: $\mathrm{G}_{4 \mathrm{k}}+\mathrm{Q}_{3 \mathrm{k}}$

When checking deflection: $\mathrm{G}_{4 \mathrm{k}}$

When checking deflection, load standard value should be adopted, so the load standard value acting on the formwork is: $\mathrm{G}_{4 \mathrm{k}}=22.4 \mathrm{kN} / \mathrm{m}^{2}$
When calculating bearing capacity, design value of load shall be adopted. If the partial coefficients of the above two loads are 1.2 and 1.4 respectively, the design value of total load acting on the formwork shall be: $\mathrm{G}_{4 \mathrm{k}}+\mathrm{Q}_{3 \mathrm{k}}=22.4 \times 1.2+4 \times 1.4=32.48 \mathrm{kN} / \mathrm{m}^{2}$

\subsection{Analysis of Simulation Results of Finite Element}

When rectangular section size is $400 \times 400 \mathrm{~mm}$ and GRC formwork thickness is $20 \mathrm{~mm}$, simulation results of GRC formwork are as follows:

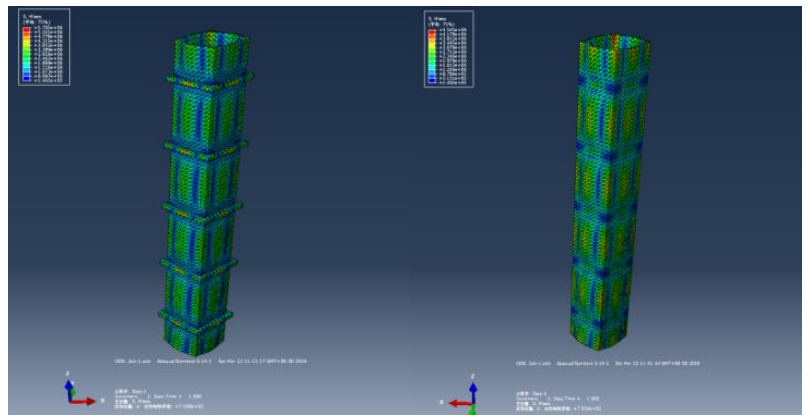

Fig.8 Stress nephogram of GRC formwork structure

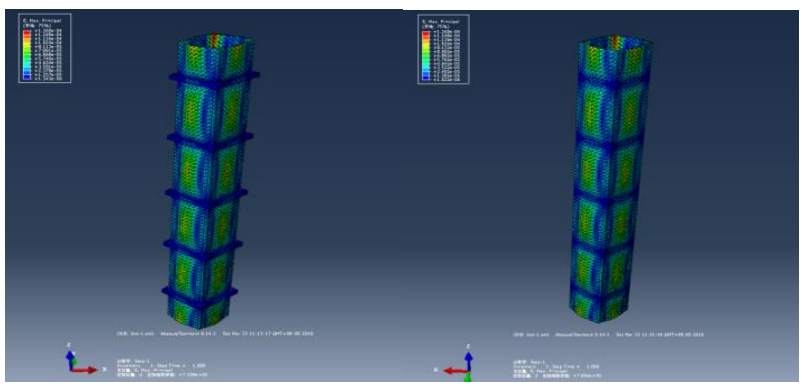

Fig.9 Strain nephogram of GRC formwork structure

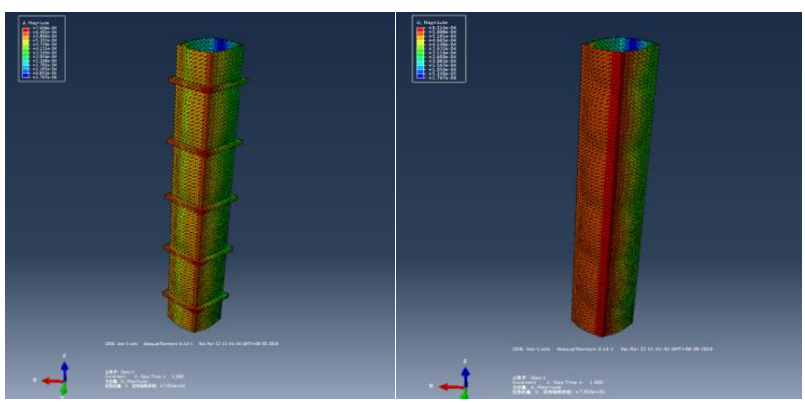

Fig.10Displacement nephogram of GRC formwork structure

Since the load is evenly distributed on the four sides of the inner side of GRC formwork, mechanical performance of each side of GRC formwork is consistent seen from both inner side and outer side of GRC formwork, and the mechanical performance of GRC formwork plate between two adjacent steel hoops is also the same. According to strain and stress nephogram on inner side of GRC formwork, when GRC formwork plate between two adjacent steel hoops is in the middle position, its stress and strain are relatively large, and when it is in the middle position of four corners of the 
whole GRC formwork, its stress and strain reach the maximum, in which the stress nephogram and strain nephogram are diffused from maximum point to periphery, and show an upward and downward symmetrical distribution trend. From simulation results, it can be seen that the maximum stress and strain generated from inner side of GRC formwork are $4.545 \mathrm{MPa}$ and $0.1360 \mathrm{~mm}$ respectively.

Judging from the strain and stress nephogram on the outer side of GRC formwork, the distribution law of strain and stress is approximately the same as that on the inner side of GRC formwork. Similarly, the stress and strain of GRC formwork plate between two adjacent steel hoops are larger when being at the middle position, and the stress reaches the maximum when being at the middle position of four corners of the plate, but the maximum strain appears at the middle position on outer side of the plate. To sum up, this shows that for the whole GRC formwork structure, the stress at the middle of four corners is always the largest, while the strain at the middle of the plate is the largest from outer side of the plate.

From displacement nephogram of GRC formwork plate, it can be clearly seen that the position with the largest displacement is always on a corner of GRC formwork plate, and the displacement on one panel contacting this corner is larger than the displacements on the other three panels. This shows that GRC formwork structure will shift towards a certain corner during concrete pouring.

\subsubsection{Comparison of GRC formwork Models with Different Thicknesses}

In order to study the influence of GRC formwork thickness on the stress of GRC formwork structure, simulation analysis of finite element is carried out on GRC formwork structures with rectangular section of $400 \times 400 \mathrm{~mm}$ and GRC formwork thicknesses of $16 \mathrm{~mm}$, $18 \mathrm{~mm}, 20 \mathrm{~mm}, 22 \mathrm{~mm}$ and $24 \mathrm{~mm}$ respectively. When drawing a rectangular section of $400 \times 400 \mathrm{~mm}$, the maximum stress, maximum strain and maximum displacement of GRC formwork structure are plotted as follows:
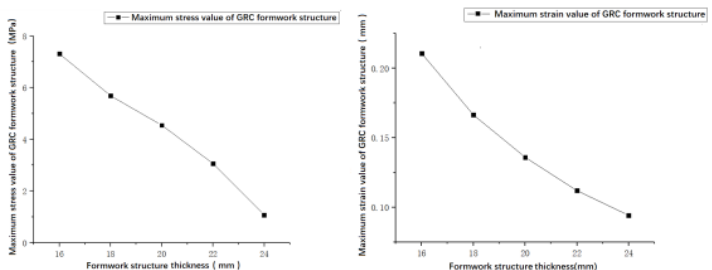

(a) Maximum stress of GRC formwork (b)Maximum strain of GRC formwork

Fig.11Maximum stress (strain) value of GRC formwork structure

As can be seen from Fig.11, when rectangular section of the GRC formwork structure is $400 \times 400$, with the increase of thickness of GRC formwork, maximum stress value and maximum strain value of GRC formwork gradually decrease, and their decrease amplitudes are not much different. However, as can be seen from Fig.12, when the thickness of GRC formwork is $18 \mathrm{~mm}$ to $20 \mathrm{~mm}$, maximum displacement value of GRC formwork is relatively small, about $1.2 \mathrm{~mm}$. This shows that when GRC formwork section is $400 \times 400$ and GRC formwork of a thickness of $18 \mathrm{~mm}$ or $20 \mathrm{~mm}$ is selected, external deformation of GRC formwork is small, so the above thicknesses of GRC formwork is more suitable for producing the prefabricated structural columns of corresponding GRC formworks.

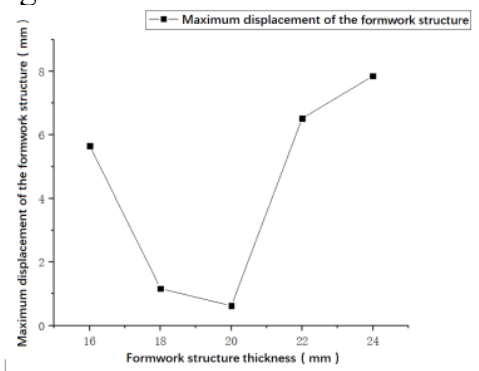

Fig.12 Maximum displacement value of GRC formwork structure

\subsubsection{Comparison of GRC Formwork Models with Different Rectangular Sections}

Similarly, in order to study the influence of different section sizes of GRC formworks on the stress of GRC formwork structure, some simulation analyses of finite element are carried out on GRC formwork structures with GRC formwork thickness of $20 \mathrm{~mm}$ and section sizes of $500 \times 500 \mathrm{~mm}$ and $600 \times 600 \mathrm{~mm}$ respectively, and the relation diagram between maximum stress and strain of GRC formwork structure and the section size of GRC formwork is obtained as follows:

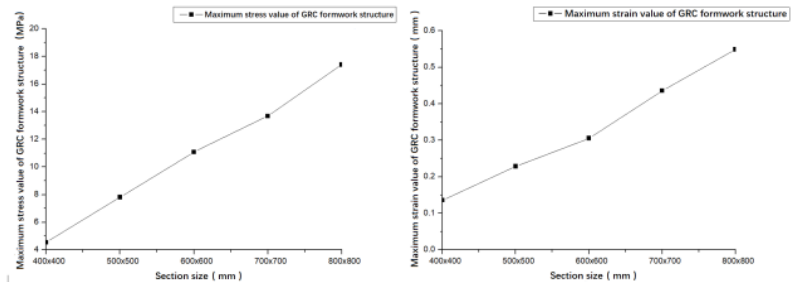

(a) Maximum stress of GRC formwork

(b) Maximum strain of GRC formwork

Fig.13 Maximum stress (strain) value of GRC formwork structure

From analysis results, it can be seen that with the increase of rectangular section size, maximum stress value and maximum strain value of GRC formwork also increase, in which strain value increases little, but load stress value increases greatly, reaching $17.419 \mathrm{MPa}$ when rectangular section is $800 \mathrm{X} 800 \mathrm{~mm}$, which may exceed maximum allowable stress of GRC formwork structure.

\section{Conclusion}

Based on the finite element simulation of the prefabricated GRC formwork columns in the concrete pouring process, and considering the influence of the thickness of the GRC formwork and the section size of 
the GRC formwork on the mechanical properties, we draw the following conclusions:

(1) In the process of concrete pouring, the load stress on the four corners of GRC formwork is the largest, and the deformation of the whole GRC formwork may be too large because of the excessive deformation on one corner. Therefore, in the process of precasting the GRC formwork column in the factory, the four corners of the GRC formwork should be strengthened to prevent excessive deformation.

(2) When the rectangular section of the GRC shell structure is fixed, increasing the thickness of the GRC shell structure can effectively reduce the load stress of the structure, but selecting the inappropriate thickness of the GRC shell will make the displacement of the structure change greatly, which needs further study. For the GRC mold shell structure with small rectangular cross-section, the thickness of GRC mold shell should be $18 \mathrm{~mm}$ or $20 \mathrm{~mm}$.

(3) When the rectangular section size of the GRC shell structure column increases gradually, the load stress and strain of the structure also increase. At this time, the thickness of the GRC shell should be properly increased to reduce the load stress and strain of the structure.

\section{Acknowledgments}

This research was financially supported by Natural Science Foundation of Anhui Province(1908085ME173), National key R \& D projects (2016YFC0701700)

\section{References}

1. WangYueming, Tang Yongzhi, Liu Kaiwei, Li Jingjing, Liu Peng, Chen Dong, Ye Zhe. Effect of fiber and rubber powder on mechanics and crack resistance of cement mortar [J]. Silicate Bulletin, 09: 2775-2781, (2018)

2. HaoXiancheng, Ma Baoguo, Li Tingjie. Effect of different latex powders on crack resistance of anti-cracking mortar [J]. 11: 19-21 +2, (2006)

3. hangEnhua, Lu Xinyan, Jiao Weili. Analysis of mechanical characteristics of self-propelled hydraulic integral external formwork for precast box girder. (Highway Traffic Technology,08(2018))

4. Li Pan, Xiao Fengjian, Jiang Jiaying. Analysis of mechanical characteristics of prefabricated box girder inner drawing hydraulic internal mold. (Highway Traffic Technology,08(2018))

5. JGJ162-2008, Safety Technical Specification for Construction Form 